\title{
Comparison of Efficacy of Treatment with Oral Ferrous Sulfate or Intravenous Iron Sucrose in the Treatment of Mild to Moderate Iron Deficiency Anemia in Pregnancy
}

\author{
Georgy J Eralil
}

\begin{abstract}
Objective: To compare the effect of treatment with either oral ferrous sulphate or intravenous iron sucrose (IVIS) on hematological parameters of women with iron deficiency anemia in pregnancy.
\end{abstract}

Methods: This prospective randomized study was interventional, conducted from January 2016 to January 2017 in Department of Obstetrics and Gynecology Sree Narayana Institute of Medical sciences.

Pregnant women Singleton pregnancy, $\mathrm{Hb}<11 \mathrm{gm}$ in $1 \mathrm{st}$ and 3rd trimester $\mathrm{Hb}<10 \mathrm{gm}$ in 2nd trimester, with hemoglobin level $7-10.9 \mathrm{~g} / \mathrm{dL}$ ferritin levels less than $<13$ microgram $/ \mathrm{L}$ and peripheral smear hypochromic microcytic anemia were enrolled into intravenous iron and oral iron groups. After detailed history and examination, laboratory investigations performed were hemoglobin, mean corpuscular volume (MCV), serum ferritin and peripheral smear. The dose for IVIS dose is calculated by ganzoni equation. Total iron deficit $(\mathrm{mg})=$ body weight $(\mathrm{kg}) \times$ [Target $\mathrm{Hb}(\mathrm{g} / \mathrm{L})$-actual $\mathrm{Hb}(\mathrm{g} / \mathrm{L})] \times 0.24+$ depot iron $(\mathrm{mg})$. A maximum IVIS is given as $200 \mathrm{mg}$ in $100 \mathrm{ml}$ normal saline as infusion over 15 to 30 minutes The remaining doses were given on alternate days. Infusions were given as outpatient basis in labor room with facilities for acute emergency care. Oral iron group received ferrous sulphate supplementation.

Results: Target hemoglobin of $11 \mathrm{~g} / \mathrm{dL}$ was attained by $66 \%$. Hemoglobin done just prior to delivery showed no statistically significant difference $(p$ value $=0.080)$ [OI group $11.83(+11.98)$ $\mathrm{g} / \mathrm{dL}$ vs. IVIS group $16.19(+11.35) \mathrm{g} / \mathrm{dL}]$. There was significant increase in serum ferritin levels with IVIS infusion There was no significant difference in antepartum or postpartum hemorrhage, infection, preterm labor, between the two groups.

Conclusion: The study concludes that oral iron increases hemoglobin comparably with IVIS. The replenishment of iron stores was good with IVIS compared with oral ferrous sulphate.

Keywords: Anaemia, Ferrous sulphate, Iron deficiency, Iron sucrose.

How to cite this article: Eralil GJ. Comparison of Efficacy of Treatment with Oral Ferrous Sulfate or Intravenous Iron Sucrose in the Treatment of Mild to Moderate Iron Deficiency Anemia in Pregnancy. Journal of Postgraduate Medicine, Education and Research, Oct-Dec 2018;52(4):167-170.

Associate Professor

Department of Obstetrics and Gynecology, Sree Narayana Institute of Medical Sciences, Aluva, Kerala, India

Corresponding Author: Georgy J Eralil, Associate Professor, Department of Obstetrics and Gynecology, Sree Narayana Institute of Medical Sciences, Aluva, Kerala, India, e-mail: georgyeralil@ yahoo.co.in
Source of support: ARISTO pharmaceuticals supplied intravenous iron sucrose for the study.

Conflict of interest: None

\section{OBJECTIVES}

Anemia affects nearly half of all pregnant women in the world increasing morbidity and mortality if left untreated. According to World Health Organisation (WHO) 2001, 52\% of pregnant women are anemic. Twenty to forty percent of maternal deaths in India are due to anemia. ${ }^{1}$ The national family health survey statistics suggest that the incidence of married women has increased to $56 \% .^{2}$ The prevalence of anemia in Kerala is $23 \%{ }^{3}$ The commonest type of anemia in pregnancy is iron deficiency anemia. ${ }^{4}$

\section{LITERATURE REVIEW}

During pregnancy, there is an increase in plasma volume compared to the increase in red cell mass. The biggest discrepancy between plasma and red cell mass happens in the late second and early third trimester with the lowest hemoglobin found at 28 to 36 weeks (Whittaker et al.).

In singleton pregnancy the average iron requirement is about $1000 \mathrm{mg}$ out of which $500 \mathrm{mg}$ is used for expansion of red blood cells (RBC) mass, $300 \mathrm{mg}$ for fetus and placenta, $200 \mathrm{mg}$ is the basal iron requirement. Between 240 and $480 \mathrm{mg}$ of iron is conserved due to amenorrhea in pregnancy. This leaves an additional requirement of 500 to $600 \mathrm{mg}$ iron/day or 4 to $6 \mathrm{mg}$ /day of absorbed iron (Stoltzfus and Dreyfuss 1998) as the absorption is less than $10 \%, 40$ to $60 \mathrm{mg}$ of iron must be made available Sharma. ${ }^{5,6}$

Iron deficiency anemia diagnosed as $\mathrm{Hb}<11.0 \mathrm{gm} / \mathrm{dL}$ in first and third trimester $\mathrm{Hb}<10.5 \mathrm{gm}$ in the second trimester, serum ferritin $<13$ micrograms $/ 1$. It is further classified as mild 10 to 10.9 moderate 7 to $9.9 \mathrm{gm} / \mathrm{dL}$ severe 4 to $6.9 \mathrm{gm} / \mathrm{dL}$ and very severe $<4 \mathrm{gm} / \mathrm{dL}$. Anemic patients are treated with either oral iron or IVIS. The rise of hemoglobin is up to $1 \mathrm{~g}$ per week (Sharma). ${ }^{6}$ Some studies have shown equal effects with the different route of administration. ${ }^{8}$ There were conflicting results regarding the outcome regarding either of drugs. ${ }^{9}$ The protocol based indication for iron sucrose is poor compliance with oral iron. 
Women with established iron deficiency anemia (IDA) will be given 100 to $200 \mathrm{mg}$ elemental iron (Pavord et al.) this would be three tablets $180 \mathrm{mg}$ of ferrous sulfate (ICMR 1992). ${ }^{10}$

Intravenous iron sucrose dose is calculated by Ganzoni equation. Total iron deficit $(\mathrm{mg})=$ body weight $(\mathrm{kg}) \times[$ Target $\mathrm{Hb}(\mathrm{g} / \mathrm{L})$-actual $\mathrm{Hb}(\mathrm{g} / \mathrm{L})] \times 0.24+$ depot iron (mg). IVIS is given as $200 \mathrm{mg}$ in $100 \mathrm{~mL}$ normal saline as an infusion over 15 to 30 minutes twice a week (Bayoumeu et al. and Fogsi 2008). ${ }^{11}$ Iron sucrose confers the benefit of excellent tolerance, minimum adverse reactions, a rapid rise in hemoglobin concentration (Van Wyck et al. 2004, 2000; Fogsi 2008)the complications are life-threatening anaphylaxis occur in $0.002 \%$, hypersensitivity reactions in $0.005 \%$ and mild adverse reactions in $35 \% .^{12}$

\section{METHODS}

The study compared the effectiveness of IVIS therapy with oral ferrous sulfate (OI) therapy in pregnant women with mild to moderate iron deficiency anemia. This prospective randomized study was carried out from January 2016 to January 2017 in the Department of Obstetrics and Gynecology Sree Narayana Institute of Medical Sciences. Ethical committee clearance was obtained from the institutional ethical committee. Pregnant women singleton pregnancy, $\mathrm{Hb}<11$ gm in 1st and 3rd trimester $\mathrm{Hb}<10$ gm in the 2nd trimester, with hemoglobin level 7 to $10.9 \mathrm{~g} / \mathrm{dL}$ ferritin levels less than $<13$ micrograms/L and peripheral smear hypochromic microcytic anemia were enrolled after taking informed consent. Women with severe anemia requiring blood transfusion any preexisting chronic medical illness like diabetes, hypertension, preeclampsia, hemoglobinopathies, malabsorption syndromes, chronic liver and renal diseases, anemia due to other causes were excluded from the study.

Patients were assigned to either the IVIS or the OI group using randomization by lottery method. Target hemoglobin in $\mathrm{g} / \mathrm{dL}$ was set at $11 \mathrm{~g} / \mathrm{dL}$ based on the WHO definition for anemia in pregnancy. After detailed history and examination, laboratory investigations performed were hemoglobin, mean corpuscular volume
$(\mathrm{MCV})$, serum ferritin and peripheral smear. Investigations were repeated after 1 month. The dose for IVIS dose is calculated by Ganzoni equation. Total iron deficit $(\mathrm{mg})=$ body weight $(\mathrm{kg}) \times$ [Target $\mathrm{Hb}(\mathrm{g} / \mathrm{L})$-actual $\mathrm{Hb}(\mathrm{g} / \mathrm{L})] \times$ $0.24+$ depot iron (mg).

Dose thus calculated was rounded up to the nearest multiple of $100 \mathrm{mg}$. Maximum IVIS is given as $200 \mathrm{mg}$ in $100 \mathrm{~mL}$ normal saline as an infusion over 15 to 30 minutes twice a week Bayoumeu et al. ${ }^{11}$ Oral ferrous sulfate was withheld during IVIS therapy. The total dose was completed by giving infusions on alternate days as an outpatient basis in the labor room with facilities for managing anaphylaxis.

Ferrous sulfate $100 \mathrm{mg}$ was used for oral therapy. Compliance was checked with weekly telephonic calls. At each visit, enquiring was detailed regarding the occurrence of adverse effects.

Statistical compilation and analysis were done with the Statistical package for social science (SPPS-17). Difference between groups was analyzed using independent sample t-test, Chi-square test or analysis of covariance appropriately. The $\mathrm{p}<0.05$ was taken as statistically significant.

There was no significant difference in baseline demographic and clinical characteristics between two groups (Table 1). The groups were comparable with regard to gravidity and parity (Table 2 ).

Sixty-six percent of the study population achieved the target hemoglobin of $11 \mathrm{~g} / \mathrm{dL}$.

Hemoglobin done just prior to delivery showed no statistically significant difference $(\mathrm{p}$-value $=0.080)$ (Table 3$)$. (OI group $11.83(+11.98) \mathrm{g} / \mathrm{dL}$ vs. IVIS group 16.19 $(+11.35) \mathrm{g} / \mathrm{dL})$. There was significant increase in serum ferritin levels (Table 4) with IVIS infusion as seen in Graph 1. There was no significant difference in antepartum or postpartum hemorrhage, infection, preterm labor, between the two groups.

\section{DISCUSSION}

The current study compares the efficacy of IVIS to oral ferrous sulfate in treating iron deficiency anemia in pregnancy. Most of the studies observed safety and speedy correction of anemia with the use of iron sucrose

Table 1: Comparison of demographic characteristics in the two groups

\begin{tabular}{llll}
\hline Parameters & Oral iron group $(n=46)$ & Intravenous iron group $(n=44)$ & $p$-value \\
\hline \multirow{2}{*}{ Age (years) } & $26.58(+4.24)$ & $26.09(+4.47)$ & 0.591 \\
& $(21-35)$ & $(19-40)$ & 0.830 \\
\hline \multirow{2}{*}{ Maternal weight $(\mathrm{kg})$} & $54.15(+9.85)$ & $53.72(+8.86)$ & 509 \\
\hline \multirow{2}{*}{ Total iron deficit } & $(40-78)$ & $(40-72)$ & \\
& $518.21(+16.1)$ & $520.59(+17.8)$ & \\
\cline { 2 - 4 } & $(503.30-576.20)$ & $(504-591.20)$ & \\
\hline
\end{tabular}

${ }^{*} \mathrm{p}$-value $<0.05$ significant, unpaired t-test, values are given as mean (standard deviation) and range 
Table 2: Comparison of gravidity and parity in the two groups

\begin{tabular}{lll}
\hline Parameters & Oral iron group $(n=46)$ & Intravenous iron group $(n=44)$ \\
\hline Gravidity $(n=90)$ & & \\
Gravidity 1 & $23(50 \%)$ & $17(38.6 \%)$ \\
Gravidity 2 & $18(39.1 \%)$ & $17(38.6 \%)$ \\
Gravidity 3 & $5(10.9 \%)$ & $5(11.4 \%)$ \\
Gravidity 4 & 0 & $5(11.4 \%)$ \\
\hline Parity $(n=38)$ & $17(89.5 \%)$ & $16(84.2 \%)$ \\
Parity 1 & $2(10.5 \%)$ & $3(15.8 \%)$ \\
Parity 2 & & \\
\hline
\end{tabular}

Table 3: Percentage increase in various parameters after treatment in the two groups

\begin{tabular}{llll}
\hline Percentage increase (value\%) & Oral iron group $(n=46)$ & Intravenous iron group $(n=44)$ & $p$-value \\
\hline Hemoglobin & $11.83(+11.98)$ & $16.19(+11.35)$ & 0.080 \\
Ferritin & $21.62(+25.62)$ & $54.80(+70.49)$ & $0.005^{*}$ \\
Mean corpuscular volume & $1.81(+4.96)$ & $5.50(+7.39)$ & $0.007^{*}$ \\
\hline
\end{tabular}

${ }^{*} \mathrm{p}$-value $<0.05$ significant, Unpaired t-test, Values are given as mean (standard deviation)

Table 4: Laboratory parameters before and after treatment in the two groups

\begin{tabular}{lllllll}
\hline & \multicolumn{3}{c}{ Before treatment } & \multicolumn{3}{c}{ After treatment } \\
\cline { 2 - 7 } Parameters & $9.79(+0.88)$ & $9.65(+0.75)$ & 0.398 & $10.88(+0.85)$ & $11.14(+0.67)$ & 0.105 \\
\hline Hemoglobin & $11.57(+3.66)$ & $12.17(+7.15)$ & 0.617 & $13.5(+3.06)$ & $15.5(+3.42)$ & $0.004^{*}$ \\
Ferritin & $83.12(+7.02)$ & $79.52(+8.81)$ & $0.035^{*}$ & $84.39(+5.31)$ & $83.45(+6.57)$ & 0.458 \\
Mean corpuscular volume & & &
\end{tabular}

${ }^{*} \mathrm{P}$ value $<0.05$ significant, Unpaired $t$ test, Values are given as mean (standard deviation)

Comparison of effect of treatment with oral ferrous sulphate or intravenous iron sucrose versus for treatment of mild to moderate iron deficiency anemia in pregnancy.

Name

Age

Hospital Number

Obstetric Score

Total Iron Deficit

Iron Replacement

Oral Intravenous

\begin{tabular}{|c|c|c|c|c|c|c|c|}
\hline Weeks & 20 & 24 & 28 & 32 & 36 & 40 & 4 \\
\hline \multicolumn{8}{|l|}{$\mathrm{Hb}$} \\
\hline \multicolumn{8}{|l|}{ Ferritin } \\
\hline \multicolumn{8}{|l|}{$\mathrm{MCV}$} \\
\hline \multicolumn{8}{|l|}{ Peripheral smear } \\
\hline \multicolumn{8}{|l|}{$\mathrm{APH} / \mathrm{PPH}$} \\
\hline \multicolumn{8}{|l|}{ Infection } \\
\hline \multicolumn{8}{|l|}{ Preterm labour } \\
\hline \multicolumn{8}{|l|}{ Wound healing } \\
\hline \multicolumn{8}{|l|}{ Cord blood } \\
\hline \multicolumn{8}{|l|}{$\mathrm{Hb}$} \\
\hline \multicolumn{8}{|l|}{ Ferritin } \\
\hline Peripheral smear & & & & & & & \\
\hline
\end{tabular}

in pregnancy. IVIS also replenished iron sucrose better than oral ferrous sulfate. ${ }^{13-16}$

As different lab parameters were used, comparison with other studies was not possible. There was a significant difference in ferritin level between the two study groups. The conclusion we could derive from it was that although anemia was corrected in either group iron stores were replenished in the intravenous iron sucrose group. Similar findings were observed by Bayoumeu et al. ${ }^{13}$

The target hemoglobin was reached in both the groups. Both groups showed a significant increase in Hemoglobin levels at 1 month when compared to the initial value. Because of physiological hemodilution and blunted erythropoietin response of second trimester significantly higher response was observed after 28 weeks. ${ }^{14}$ 


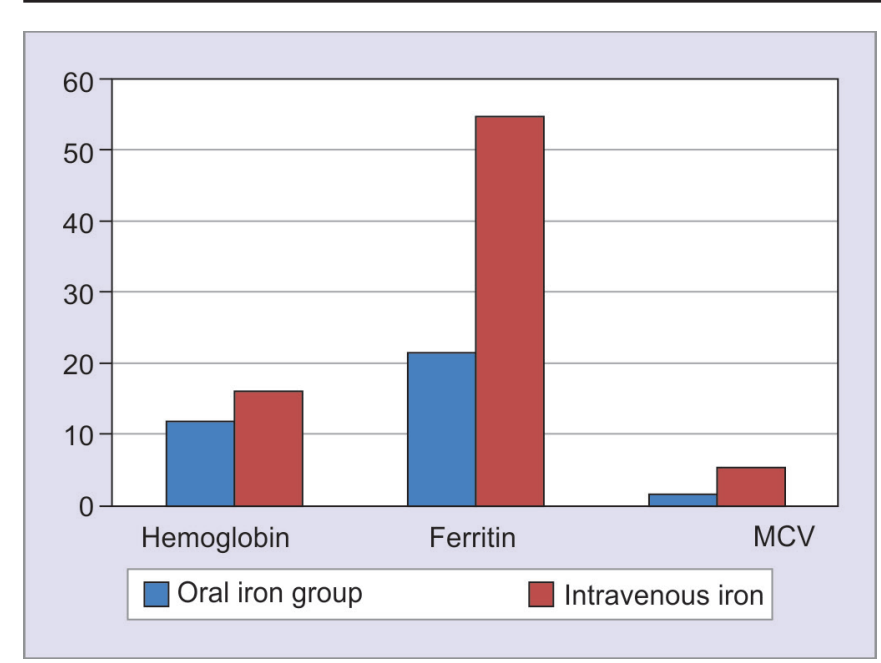

Graph 1: Percentage increase in various parameters after treatment in the two groups

So IVIS is the preferable treatment of moderate anemia in the third trimester.

An oral iron therapy group had $23 \%$ of gastrointestinal side effects in comparison to $31 \%$ in other studies. ${ }^{15,16}$ Adverse drug reactions noted in intravenous therapy were giddiness, vomiting, and rashes. There were no episodes of anaphylaxis supporting the safety in pregnancy.

Intravenous iron sucrose complex releases iron rapidly to endogenous iron-binding proteins. It has a half-life of about 6 hours. ${ }^{17}$ It does not get deposited in the parenchymal tissue hence increasing ferritin levels.

On comparison of the cost factor, oral iron therapy was found cheaper and easy for administration. A back upsetting for treatment for anaphylaxis was mandatory for IVIS.

The limitations of this study were small study sample size and absence of follow-up in the postnatal period to determine whether hemoglobin levels were maintained during lactation because of higher stores after intravenous iron therapy.

The study concludes that oral iron increases hemoglobin comparably with IVIS. The replenishment of iron stores was good with IVIS compared with oral ferrous sulfate.

Women may become anemic again during lactation if their iron stores are not replenished. Hence replenishing stores is significant in our country where ongoing postnatal follow-up is often absent.

The absence of major adverse events with iron sucrose proves it a safe, efficacious treatment of mild to moderate IDA in pregnant women.

\section{REFERENCES}

1. Bhatt R. Maternal mortality in India-FOGSI-WHO study JOGI 1997;47:207-214.

2. Bhatt R. Poor iron compliance-the way out JOGI 1992;47: 185-190.

3. International institute for population sciences and Macro international2007. National Family health survey NFHS-3 2005-2006 India: key findings Mumbai:IIPS8.

4. National Family health survey. NFHS-11 Mumbai India: International Population Studies. 2000.

5. Stoltzfus R, Dreyfuss M L. Guidelines for the use of iron supplements to prevent and treat iron deficiency anemia. Geneva INACG,WHO,UNICEF, 1998.

6. SharmaJB. Nutritional anaemia during pregnancy in third world countries. Progress in obstetrics and gynaecology. 2003;15: 103-122.

7. ACOG. Anemia in pregnancy ACOG practice bulletin no 95, 2008.

8. Westad S, Backe B, Salvesen KA, Nakling J, Økland I, Borthen $\mathrm{I}$, et al. A 12-week randomised study comparing intravenous iron sucrose versus oral ferrous sulphate for treatment of postpartum anemia. Acta obstetricia et gynecologica Scandinavica. 2008 Jan 1;87(9):916-923.

9. Sharma JB. Nutritional anaemia during pregnancy in third world countries. Progress in obstetrics and gynaecology. 2003;15:103-122.

10. Indian council of medical research. Evaluation of the national nutritional anemia prophyllaxis programme. Task force study. New Delhi: ICMR. 1989.

11. Bayoumeu F, Subiran-Buisset C, Baka NE, Legagneur H, Monnier-Barbarino $\mathrm{P}$, Laxenaire MC. Iron therapy in iron deficiency anemia in pregnancy: intravenous route versus oral route. European Journal of Obstetrics \& Gynecology and Reproductive Biology. 2005 Dec 1;123:S15-S19.

12. Van Wyck DB, Cavallo G, Spinowitz BS, Adhikarla R, Gagnon S, Charytan C, et al. Safety and efficacy of iron sucrose in patients sensitive to iron dextran: North American clinical trial. American Journal of Kidney Diseases. 2000 Jul 1;36(1):88-97.

13. Bayoumeu F, Subiran-Buisset C, Baka NE, Legagneur $H$, Monnier-Barbarino P, Laxenaire MC. Iron therapy in iron deficiency anemia in pregnancy: Intravenous route versus oral route. Am J Obstet Gynecol. 2002;186:518-522.

14. Carretti N, Paticchio MR. Intravenous iron therapy in pregnancy anemia: Hematological response in relation to gestational age. Gynecol Obstet Invest. 1999;47:217-222.

15. Al-Momen AK, al-Meshari A, al-Nuaim L, Saddique A, Abotalib Z, Khashogji T, et al. Intravenous iron sucrose complex in the treatment of iron deficiency anemia during pregnancy. Eur J Obstet Gynecol Reprod Biol. 1996;69:121-124.

16. Al RA, Unlubilgin E, Kandemir O, Yalvac S, Cakir L, Haberal A. Intravenous versus oral iron for treatment of anemia in pregnancy: a0 randomized trial. Obstet Gynecol. 2005;106:1335-1340.

17. Silverstein SB, Rodgers GM. Parenteral iron therapy options. Am J Hematol. 2004;76:74-78. 